Article

\title{
Preparation of the Yellow-Colored Aluminum Pigments with Double-Layer Structure Using a Crosslinked Copolymeric Dye
}

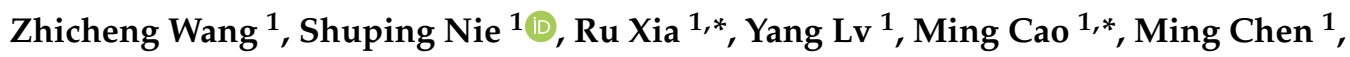 \\ Qiannian Dong ${ }^{2}$, Lifen Su ${ }^{1}$, Peng Chen ${ }^{1}$, Bin Yang ${ }^{1}$, Jibin Miao ${ }^{1}$, Zhengzhi Zheng ${ }^{1}$ and \\ Jiasheng Qian ${ }^{1}$ \\ 1 Key Laboratory of Environment-Friendly Polymeric Materials of Anhui Province, School of Chemistry and \\ Chemical Engineering, Anhui University, Hefei 230601, China; honestwzc@163.com (Z.W.); \\ spnam@sina.com (S.N.); lightmisaya@sina.com (Y.L.); cm630309441@163.com (M.C.); \\ ausulf@gmail.com (L.S.); chpecp@126.com (P.C.); beanyoung@163.com (B.Y.); \\ lingxiaoyu1003@163.com (J.M.); 10006@ahu.edu.cn (Z.Z.); qianjsh@ahu.edu.cn (J.Q.) \\ 2 Hefei Sunrise Aluminum Pigments Co. Ltd., Hefei 231131, China; dongqn2005@126.com \\ * Correspondence: xiarucn@sina.com (R.X.); mcao@ahu.edu.cn (M.C.); Tel.: +86-551-6386-1480 (R.X.)
}

Received: 4 September 2018; Accepted: 2 October 2018; Published: 4 October 2018

check for updates

\begin{abstract}
Colorization for fabricating aluminum pigments has broad application prospects in recent years. In this study, yellow-colored aluminum pigments with the double-layer structure $\mathrm{Al} @ \mathrm{SiO}_{2} @ \mathrm{PFMV}$ were prepared using a sol-gel method. A crosslinked copolymeric dye (PFMV) was firstly synthesized by radical polymerization using vinyl triethoxysilane (VTES) and a small molecular dye (FGMAC) as monomers. Then, colored aluminum pigments were prepared by hydrolysis and condensation of the copolymers on the surface of aluminum pigments. SEM, AFM, FTIR, and XPS were used to characterize the surface morphology and chemical structure of the colored aluminum pigments. It was found that the colored aluminum pigments have a heterogeneous and smooth surface layer. The anticorrosion results showed that the colored aluminum pigments had better chemical stability with significantly improving corrosion resistance compared to raw aluminum pigments and $\mathrm{Al} @ \mathrm{SiO}_{2}$ with the single-layer coating. Chromatism analysis indicated that the lightness of $\mathrm{Al} @ \mathrm{SiO}_{2} @ \mathrm{PFMV}$ pigments decreased slightly and the color changed from silver-gray to yellow.
\end{abstract}

Keywords: aluminum pigments; crosslinked copolymeric dye; corrosion resistance

\section{Introduction}

Aluminum pigments, a kind of ultrathin flaky aluminum powders, have been widely used in printing, painting and coating industry owing to their excellent metallic luster, covering capability, and "flip-flop" effect [1-4]. However, a severe problem is that aluminum can easy to react with water under the acid or alkali condition, which not only results in gloss decrease, but also affects the metallic luster, and even causes security risks [5-8]. Therefore, it is necessary to develop a method for improving the corrosion resistance of aluminum pigments on the surface.

Among various kinds of improving the anticorrosion properties of aluminum pigments, one method is to use anticorrosion inhibitor with special functional groups, which can adsorb on the surface of aluminum pigments, such as citric acid, aminophenols, vanillin, and so on [9-12]. Compared with adsorption of anticorrosion inhibitor, the other promising method is forming an inorganic layer or organic layer on the surface of aluminum pigments. For example, Kiehl firstly proposed the inorganic $\mathrm{SiO}_{2}$ encapsulation of aluminum pigments using tetraethoxysilane (TEOS) as a precursor with a sol-gel method [13]. Zhang et al. reported a coated aluminum pigments with TEOS 
using the similar method, the results showed that the corrosion protection factor can reach $99.3 \%$ [7]. Zhou et al. found that aluminum pigments coated with $\mathrm{SiO}_{2}$ and $\mathrm{TiO}_{2}$ with the double- layer structure to improve the dispersibility and anticorrosive properties [14]. Another encapsulated method is to modify the pigments using organic layer. Synthetic strategies including in situ polymerization or grafting polymer chains onto the aluminum pigments have been developed $[4,15-18]$ and results in the formation of a dense layer on the surface of aluminum pigments. All these proposed methods have achieved significant progress for improving the corrosion resistance of aluminum pigments. However, it should be noted that inorganic coatings, such as $\mathrm{SiO}_{2}$ or $\mathrm{TiO}_{2}$, showed excellent stability but have poor compatibility with a polymeric matrix when using in painting or printing industry $[19,20]$. Organic coatings using polymers showed good compatibility but the chemical stability is not enough in corrosion medium compared to inorganic coatings, especially in some extreme environment [21]. Recently, the aluminum pigments were coated with hybrid layers, inferred as organic-inorganic mixed coating, which not only improved their anti-corrosion property, but also enhanced their dispersivity and compatibility $[22,23]$.

In addition to the anticorrosion properties, colorization for fabricating aluminum pigments has broad application prospects and is strongly welcomed in recent years [24]. The colored aluminum pigments not only have metallic luster, but also have chromatic colors, which is not the case compared to raw aluminum pigments. Usually, depositing a layer of metal oxides on the surface of aluminum pigments is most often used to prepare colorful aluminum pigments, such as iron oxide and cobalt oxide $[25,26]$. Colored aluminum pigments were prepared by this method have the characteristics of good chemical resistance and weather resistance. However, it is difficult to achieve vivid color using this method. In addition, their compatibility with polymeric matrix is poor when in use in painting or printing industry. To solve these problems, depositing organic pigments onto the surface of aluminum pigments with the aid of polymer can not only bring bright colors, but also improve their anti-corrosion properties and compatibility. For example, Fu et al. prepared a polymer encapsulated colorful aluminum pigment by an in-situ polymerization method, which was stable in strong alkaline or acidic conditions with good near-infrared reflectance [27]. A colored polymer/aluminum hybrid pigment was synthesized by copolymerizing with $n$-butyl acrylate and styrene on the surface of aluminum pigments. They found that both the length of the grafted chains and the dye/styrene molar ratio influenced the color of the resultant hybrid material [28].

In this paper, the main object is to introduce a method for the synthesis of colored aluminum pigments with the double-layer structure using a cross-linked copolymeric dye. It is expected that combination of the organic-inorganic mixed coating with introducing the coloring dyes, may produce colored aluminum pigments with better anti-corrosion properties. To obtain the desired effect, we firstly synthesized a new kind of copolymeric dye by radical polymerization using VTES and a small molecular dye FGMAC as monomers (Scheme 1a). Secondly, the colored aluminum pigments were prepared by hydrolysis and condensation of the copolymers on the surface of aluminum pigments (Scheme $1 \mathrm{~b}$ ). This method for preparation of the colored aluminum pigments has the following merits: (1) The dyes were introduced by covalent chemical bonds to achieve the purpose of coloring, which reduces the color fading over a long period of time compared to physical adsorption. (2) The double-layer structure will offer sufficient protection, reducing the corrosion on the surface of aluminum pigments. The chemical structure of the PFMV was analyzed. The surface morphology and chemical structure of the modified aluminum pigments were characterized by SEM, AFM, FTIR, and XPS. The anticorrosion properties and color performance of the prepared ${\mathrm{Al} @ S i \mathrm{~S}_{2} @ \mathrm{PFMV}}$ pigments were also investigated. 
(a)

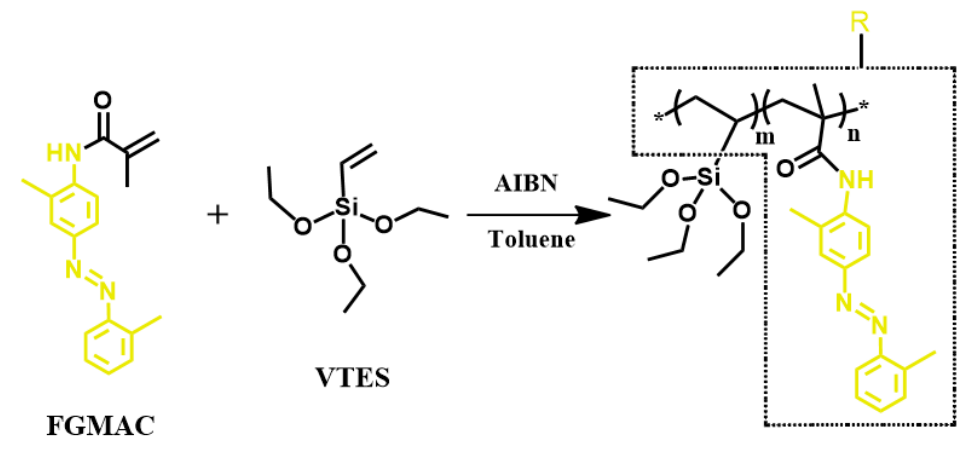

(b)
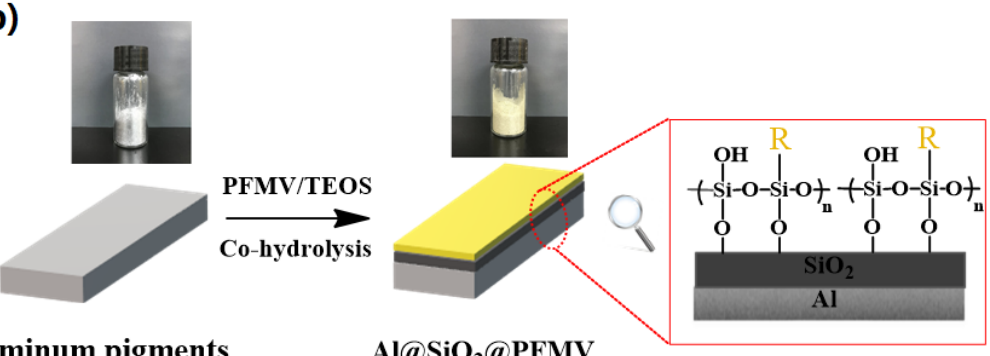

Aluminum pigments

Al@SiO $@$ PFMV

Scheme 1. Schematic illustration of the preparation of PFMV (a) and yellow-colored $\mathrm{Al}_{\mathrm{SSiO}} @ \mathrm{PFMV}$ pigments with double-layer structure (b).

\section{Materials and Methods}

\subsection{Materials}

Aluminum pigments were purchased from Hefei Sunrise Aluminum Pigments Co., Ltd. (Hefei, China). Azobisisobutyronitrile (AIBN), tetraethoxysilane (TEOS), 4-amino-2',3-dimethylazobenzene (FG), methacryloyl chloride (MAC), vinyltriethoxysilane (VTES), andbutylatedhydroxytoluene (BHT) were provided by Aladdin Co. Ltd., Shanghai, China. All other chemicals were purchased from Sinopharm Chemical Reagent Co., Ltd. (Shanghai, China), and used without further purification.

\subsection{Preparation of FGMAC}

The FGMAC was prepared according to the procedure described in the literature with slight modification [29]. $3.21 \mathrm{~g}$ of $\mathrm{FG}, 2.07 \mathrm{~g}$ of $\mathrm{Et}_{3} \mathrm{~N}$ and $0.015 \mathrm{~g}$ of BHT were dissolved in $36 \mathrm{~mL}$ ether at $0{ }^{\circ} \mathrm{C} .2 .82 \mathrm{~g}$ of MAC was added dropwise into the solution under nitrogen atmosphere. The solution was stirred at room temperature overnight. The precipitate was filtered and the filtrate is dissolved in chloroform. The solution was washed with $5 \% \mathrm{HCl}$, water, $1 \mathrm{~mol} / \mathrm{L} \mathrm{NaOH}$, and distilled water. The organic phase was dried with sodium sulfate and then the solvent was evaporated. The product was recrystallized from dichloromethane/hexane (1/3) with an orange solid FGMAC (yield 58\%).

${ }^{1} \mathrm{H}$ NMR $\left(\mathrm{CDCl}_{3}\right): \delta=2.12 \mathrm{ppm}\left(\mathrm{s}, 3 \mathrm{H},=\mathrm{C}-\mathrm{CH}_{3}\right), 2.40 \mathrm{ppm}\left(\mathrm{s}, 3 \mathrm{H}, \mathrm{CH}_{3}\right.$ ortho to $\left.-\mathrm{HN}-\mathrm{C}=\mathrm{O}\right)$, $2.72 \mathrm{ppm}\left(\mathrm{s}, 3 \mathrm{H},-\mathrm{CH}_{3}\right.$ ortho to $\left.\mathrm{N}=\mathrm{N}\right), 5.53 \mathrm{ppm}$ and $5.88 \mathrm{ppm}\left(2 \mathrm{~s}, 2 \mathrm{H},-\mathrm{C}=\mathrm{CH}_{2}\right), 7.33-7.54 \mathrm{ppm}$ $(\mathrm{m}, 3 \mathrm{H}$, aromatic $\mathbf{H}$ protons), $7.61-7.86 \mathrm{ppm}(\mathrm{m}, 4 \mathrm{H}$, aromatic $\mathbf{H}$ protons ortho to $\mathrm{N}=\mathrm{N}$ and $\mathrm{HN}-\mathrm{C}=\mathrm{O})$, and $8.28 \mathrm{ppm}(\mathrm{d}, 1 \mathrm{H},-\mathrm{HN}-\mathrm{C}=\mathrm{O})$.

\subsection{Preparation of PFMV}

$0.586 \mathrm{~g}$ of FGMAC, $3.8 \mathrm{~g}$ of VTES and $0.044 \mathrm{~g}$ of AIBN were dissolved in $6 \mathrm{~mL}$ toluene. The solution was placed into a three-necked flask under nitrogen atmosphere. After three freeze-pump-thaw cycles, the above solution was heated at $70^{\circ} \mathrm{C}$ for $48 \mathrm{~h}$. After cooling to room temperature, the reaction mixture was poured into $200 \mathrm{~mL}$ ether. The precipitate was isolated, redissolved in chloroform, and purified by reprecipitation twice in the ether. The products were dried in a vacuum oven at room temperature for $24 \mathrm{~h}$, yielding a red-brown solid at $83 \%$. 
${ }^{1} \mathrm{H} \mathrm{NMR}\left(\mathrm{CDCl}_{3}\right): \delta=1.26 \mathrm{ppm}\left(-\mathrm{CH}_{2} \mathrm{CH}_{3}, \mathrm{CH}_{3}-\mathrm{C}\right.$ and $\left.-\mathrm{CH}_{2}-\mathrm{CH}-\mathrm{Si}-\right) .1 .55 \mathrm{ppm}\left(-\mathrm{CH}_{2} \mathrm{CCH}_{3}\right)$, 1.63-1.73 ppm ( $\left.-\mathrm{CH}_{2} \mathrm{CH}-\mathrm{Si}-\right)$, $2.40 \mathrm{ppm}\left(\mathrm{CH}_{3}\right.$ ortho to $\left.-\mathrm{HN}-\mathrm{C}=\mathrm{O}\right), 2.72 \mathrm{ppm}\left(\mathrm{CH}_{3}\right.$ ortho to $\left.\mathrm{N}=\mathrm{N}\right)$, $3.73 \mathrm{ppm}\left(\mathrm{CH}_{3} \mathrm{CH}_{2}-\mathrm{O}\right), 7.33 \mathrm{ppm}$ (aromatic $\mathbf{H}$ protons), $7.52 \mathrm{ppm}$ (aromatic $\mathbf{H}$ proton ortho to $\mathrm{N}=\mathrm{N}$ and $\mathrm{CH}_{3}$ ), 7.60-7.62 ppm (aromatic $\mathbf{H}$ proton ortho to $\mathrm{N}=\mathrm{N}$ ), $7.79 \mathrm{ppm}$ (aromatic $\boldsymbol{H}$ proton ortho to $\mathrm{NH}), 7.83-7.85$ ppm (aromatic $\boldsymbol{H}$ proton ortho to $\mathrm{N}=\mathrm{N}$ ), and 8.26-8.29 ppm (-NH-).

\subsection{Preparation of $A l @ S i O_{2} @ P F M V$}

$2.0 \mathrm{~g}$ of aluminum pigments were dispersed in $60 \mathrm{~mL}$ ethanol, and then ultrasonicated for $10 \mathrm{~min}$ to obtain the dispersed suspension. The suspension was transferred into a three-necked flask. Afterward, the prepared solution A ( $3 \mathrm{~g}$ PFMV, $2 \mathrm{~g}$ TEOS and $30 \mathrm{~mL}$ absolute ethanol) and solution B (3.0 g ammonia, $5 \mathrm{~mL}$ distilled water and $30 \mathrm{~mL}$ absolute ethanol) were added dropwise to the above solution at the same time. The mixture was stirred at $50{ }^{\circ} \mathrm{C}$ for $6 \mathrm{~h}$. When the reaction was over, the dispersion was centrifuged to obtain the precipitate. The precipitate was washed by absolute ethanol for three times, dried in a vacuum oven at $60{ }^{\circ} \mathrm{C}$ for $24 \mathrm{~h}$ to obtain the $\mathrm{Al}_{\mathrm{S}} \mathrm{SiO} \mathrm{O}_{2} @ \mathrm{PFMV}$ composites. $\mathrm{Al} @ \mathrm{SiO}_{2}$ was prepared using the same process with $2 \mathrm{~g}$ of TEOS as the precursor.

\subsection{Characterization}

The ${ }^{1} \mathrm{H}$ NMR spectra was carried out on a Bruker AVANCE III (Billerica, MA, USA) at $400 \mathrm{MHz}$ $\left({ }^{1} \mathrm{H}\right)$ using $\mathrm{CDCl}_{3}$ as a solvent. The molecular weight and polydispersity of polymers were measured by GPC (PL-120, Agilent Technologies, Santa Clara, CA, USA). Polystyrenes (PS) were used for the calibration with THF as the eluent $(1 \mathrm{~mL} / \mathrm{min})$. The chemical structures of the aluminum pigments were analyzed by the Fourier transform infrared spectroscopy (FTIR) (NEXUS-870, Nicolet, Madison, WI, USA) scanning from 4000 to $500 \mathrm{~cm}^{-1}$. X-ray photoelectron spectroscopy (XPS, VG, Altrincham, UK) analysis was carried out on a ESCALAB-MK-II spectrometer equipped with AlKa X-ray source, operated at $150 \mathrm{~W}$. Scanning electron microscope (SEM, S-4800, Hitachi, Japan) was used to observe the morphologies of the modified aluminum pigments. The surface roughness of the aluminum pigments was characterized by Atomic force microscope (AFM, D3000, Shanghai Zhuolun MicroNano Equipment Co., Ltd., Shanghai, China). Thermo degradation was detected by a thermo gravimetric analyzer (Pyris-1, PerkinElmer, Waltham, MA, USA) under nitrogen atmosphere ranging from 50 to $800^{\circ} \mathrm{C}$ at a heating rate of $20^{\circ} \mathrm{C} / \mathrm{min}$. The color performance of the pigments was analyzed by an MA-94 color analyzer (X-Rite, Grand Rapids, MI, USA). The particle size was analyzed using a S3500 analyzer (Microtrac, Montgomeryville, PA, USA). Corrosion resistance test was accomplished using the method described in the literature [16], by placing $0.1 \mathrm{~g}$ aluminum pigments in $\mathrm{pH} 1.0$ hydrochloric acid or $\mathrm{pH}$ 12 sodium hydroxide solution for $168 \mathrm{~h}$ according to the quantity of hydrogen.

\section{Results and Discussion}

Colored aluminum pigments with the double-layer structure $\mathrm{Al}_{\mathrm{SiO}} @ \mathrm{PFMV}$ were prepared by a two-step process. Firstly, PFMV was synthesized by radical copolymerization using VTES and FGMAC as monomers; the products could be easily separated by precipitation in ethyl ether, obtained in $83 \%$ yield. Secondly, the PFMV was introduced to the aluminum surface co-hydrolyzed with TEOS as precursors. Due to a large number of hydroxyl groups present on the surface of aluminum pigments, the ethoxy groups of TEOS and PFMV could be hydrolyzed and condensed on the surface of aluminum pigments using aqueous ammonia as a catalyst (Scheme 1).

\subsection{Preparation and Characterization of PFMV}

The structure of the PFMV copolymers was characterized by ${ }^{1} \mathrm{H}$ NMR. As shown in Figure 1. The appearance of the new peaks both from FGMAC and VTES, and the disappearance of peaks $\left(\mathrm{CH}_{2}=\mathrm{CH}-\right)$ around 5.53 and $5.88 \mathrm{ppm}$ attributed to groups from FGMAC and $5.3 \mathrm{ppm}$ ascribe to the $\mathrm{CH}_{2}=$ groups from VTES. The molar ratio of VTES to FGMAC was $1 / 4$, which can be calculated by the integral ratio of (3.71-3.73 ppm, $-\mathrm{CH}_{2}-\mathrm{O}$ ) in the VTES blocks and (2.40 ppm, $\mathrm{CH}_{3}$ ortho to $\mathrm{N}-\mathrm{C}=\mathrm{O}$ ) in 
FGMAC blocks. The copolymers were further characterized by GPC with polystyrene as standards. As shown in Figure 2, the GPC curve presented a unimodal distribution, good symmetry, and no tail phenomenon. The $M_{\mathrm{n}}$ of the copolymers is about $7121 \mathrm{Da}$ and the PDI $\left(M_{\mathrm{w}} / M_{\mathrm{n}}\right)$ is 1.43.

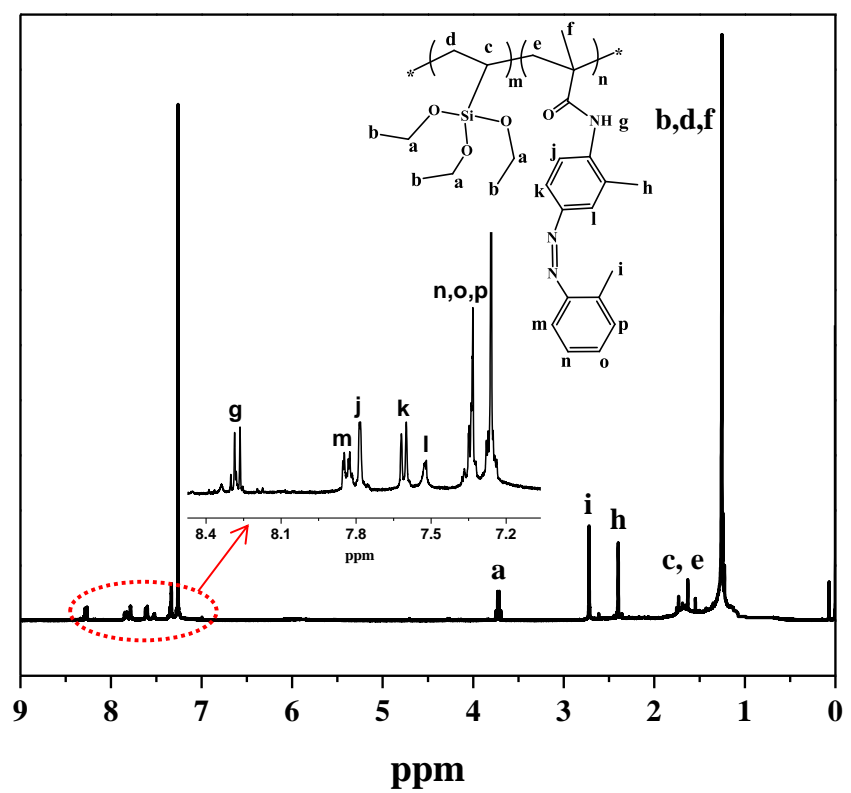

Figure 1. ${ }^{1} \mathrm{H}$ NMR spectra of PFMV.

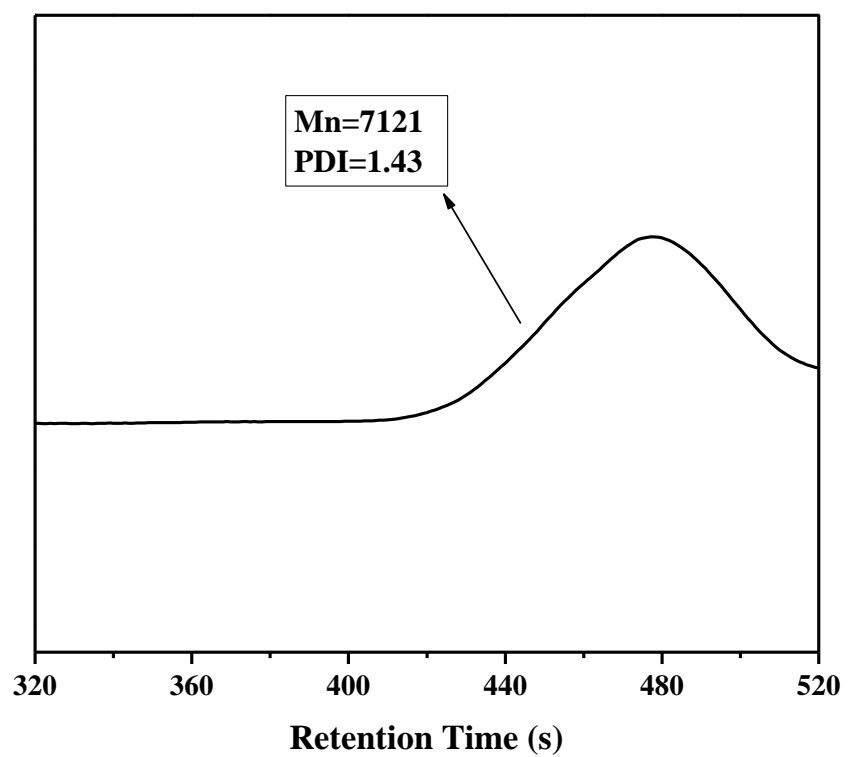

Figure 2. GPC spectra of PFMV.

Figure 3 showed the FTIR spectra of VTES (curve a), FGMAC (curve b) and PFMV (curve c). The spectrum of the VTES (curve a) exhibited characteristic absorptions of Si-O-R at $1085 \mathrm{~cm}^{-1}$, $\mathrm{C}=\mathrm{C}$ at $1640 \mathrm{~cm}^{-1}$ and $\delta \mathrm{CH}_{3}$ at $1400 \mathrm{~cm}^{-1}$ [19]. The spectrum of the FGMAC (curve b) exhibits characteristic peaks at $3276 \mathrm{~cm}^{-1}(v \mathrm{NH}), 1664 \mathrm{~cm}^{-1}\left(v \mathrm{C}=\mathrm{O}\right.$ amide I), $1625 \mathrm{~cm}^{-1}(\delta \mathrm{NH}), 1517 \mathrm{~cm}^{-1}(v$ $\mathrm{C}=\mathrm{C}$ aromatic), $1447-1370 \mathrm{~cm}^{-1}\left(\delta \mathrm{CH}_{3}\right), 1260 \mathrm{~cm}^{-1}(\vee \mathrm{C}-\mathrm{N}), 920 \mathrm{~cm}^{-1}(\delta \mathrm{CH}=\mathrm{C})$, and $887-760 \mathrm{~cm}^{-1}$ $\left(\delta \mathrm{CH}\right.$ aromatic) [29]. For PFMV (curve c), there are clearly absorptions at $3276 \mathrm{~cm}^{-1}$ of NH, $1085 \mathrm{~cm}^{-1}$ of Si-O-R and many characteristic peaks which showed in curve (b), and the disappearance of peaks around $1640 \mathrm{~cm}^{-1}$ and $920 \mathrm{~cm}^{-1}$ attributed to $C=C$ groups. All these results indicated that PFMV was synthesized successfully. 


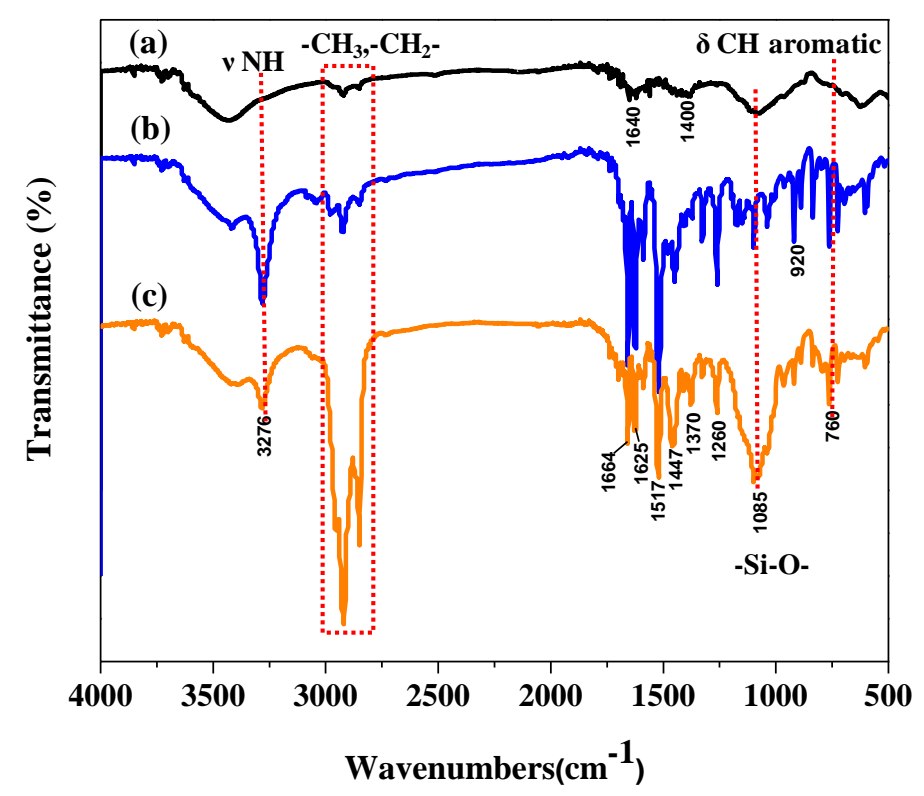

Figure 3. FTIR spectra of VTES (a), FGMAC (b) and PFMV (c).

\subsection{Preparation and Characterization of the $A l @ \mathrm{SiO}_{2} @ P F M V$}

\subsubsection{FTIR Analysis}

Figure 4 showed the FTIR spectra of raw aluminum pigments (curve a), $\mathrm{Al}_{\mathrm{SiO}}$ (curve b),

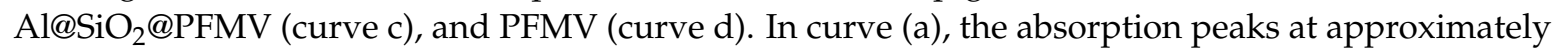
$3400 \mathrm{~cm}^{-1}$ can be attributed to the -OH groups. For $\mathrm{Al} @ \mathrm{SiO}_{2}$, aluminum pigment modified with pure TEOS exhibited new characteristic absorptions of Si-O-Si at $1050 \mathrm{~cm}^{-1}$ [19]. For $\mathrm{Al} @ \mathrm{SiO}_{2} @ \mathrm{PFMV}$, the characteristic absorptions of Si-O-Si at $1085 \mathrm{~cm}^{-1}, v \mathrm{NH}$ at $3276 \mathrm{~cm}^{-1}, v \mathrm{C}=\mathrm{O}$ amide I at $1664 \mathrm{~cm}^{-1}$, $\delta \mathrm{NH}$ at $1625 \mathrm{~cm}^{-1}, v \mathrm{C}-\mathrm{N}$ at $1260 \mathrm{~cm}^{-1}$, benzene of $v \mathrm{C}=\mathrm{C}$ aromatic at $1517 \mathrm{~cm}^{-1}$, and $\delta \mathrm{CH}$ aromatic at $760 \mathrm{~cm}^{-1}$ were observed, which suggested that the hydroxyl groups of the aluminum pigments underwent condensation reactions with PFMV and TEOS to form inorganic-organic layer.

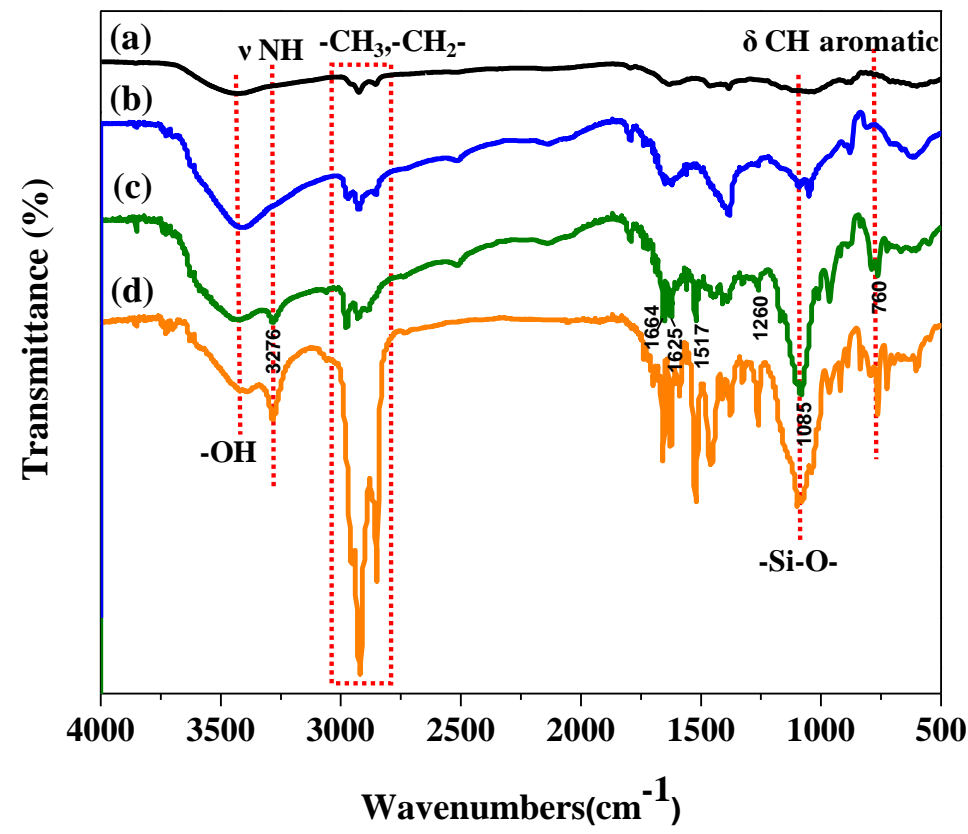

Figure 4. FTIR spectra of raw aluminum pigments (a), $\mathrm{Al} @ S i O_{2}$ (b), $\mathrm{Al} @ S i O_{2} @ P F M V ~(c)$, and PFMV (d). 


\subsubsection{XPS Analysis}

To further characterize the modified aluminum pigments, surface chemical changes and chemical compositions were analyzed by XPS. The elemental contents of three samples including raw aluminum pigments, $\mathrm{Al} @ \mathrm{SiO}_{2}$ and $\mathrm{Al}_{\mathrm{SSiO}} @ \mathrm{PFMV}$ were listed in Table 1. As shown in Figure 5a, the characteristic peaks of Al2p can be found at approximately $71.9 \mathrm{eV}$. The O1s and C1s elements at 285.1 and $536.3 \mathrm{eV}$ can also be observed, which could be attributed to the residual higher fatty acid or solvent oil used in the manufacturing process of aluminum pigments. After being modified with TEOS, the spectra showed new peaks at binding energy of 103.1 and $151.5 \mathrm{eV}$ (Figure 5b) [30], which were ascribed to Si2p and Si2s. The content of Al element decreased from $49.78 \%$ to $3.93 \%$ and the C element decreased from $25.4 \%$ to $12.25 \%$. For Al@SiO ${ }_{2} @ P F M V$, with the exception of the Si2p and Si2s (103.1 and $151.5 \mathrm{eV})$ peaks, the new element $\mathrm{N}(\mathrm{N} \mathrm{1s}, 400.1 \mathrm{eV})$ appeared (Figure 5c) [23]. In addition, the content of Al2p sharply decreased to $3.74 \%$, and C1s increased from $25.4 \%$ to $40.02 \%$, suggested that TEOS and PFMV have been successfully coated on the surface of aluminum pigments and formed a relative denser encapsulation than TEOS.
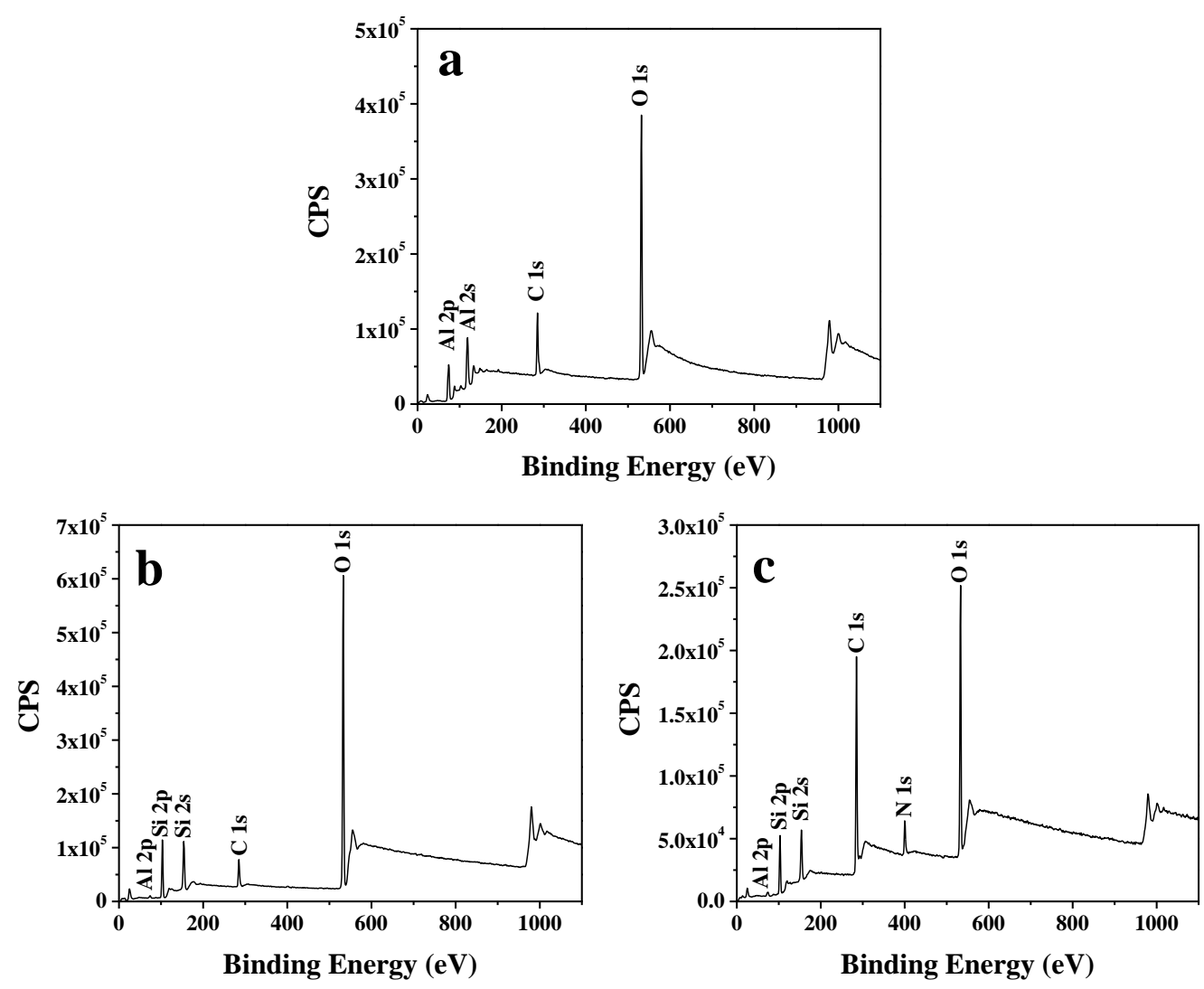

Figure 5. XPS spectra of raw aluminum pigments (a); $\mathrm{Al} @ \mathrm{SiO}_{2}(\mathbf{b})$; and $\mathrm{Al} @ \mathrm{SiO}_{2} @ \mathrm{PFMV}$ (c).

The surface chemical changes of the samples were further conducted to elucidate the chemical bonds, which were fitted using the software XPSPEAK. The high-resolution O1s spectra of $\mathrm{Al} @ \mathrm{SiO}_{2} @ \mathrm{PFMV}$ was shown in Figure 6a, it was found that the O1s peak shifted from $531.6 \mathrm{eV}$ to $532.9 \mathrm{eV}$ [23], suggesting that the chemical environment changed after the coating process. As shown in Figure $6 \mathrm{~b}$, the spectra of raw aluminum pigments showed a double peak, the Al2p peak at $71.9 \mathrm{eV}$ and $74.5 \mathrm{eV}$ was attributable to aluminum and $\mathrm{Al}_{2} \mathrm{O}_{3}$, respectively. After being modified with PFMV, the Al2p peak shifted from 74.5 to $75.0 \mathrm{eV}$, suggesting that the chemical environment corresponding to the Al-O bond changed. This chemical shift indicated that new Al-O-Si bonds were formed on the aluminum surface after the coating [19]. 
Table 1. Elemental contents on the surface of aluminum pigments.

\begin{tabular}{cccccc}
\hline \multirow{2}{*}{ Sample } & \multicolumn{5}{c}{ Elemental Contents (PP, at\%) } \\
\cline { 2 - 6 } & Al & C & O & Si & N \\
\hline raw Al & 49.78 & 25.4 & 24.82 & $/$ & $/$ \\
$\mathrm{Al@SiO}$ & 3.93 & 12.25 & 42.6 & 41.22 & $/$ \\
$\mathrm{Al} @ \mathrm{SiO}_{2} @ \mathrm{PFMV}$ & 3.74 & 40.02 & 24.83 & 24.38 & 7.03 \\
\hline
\end{tabular}
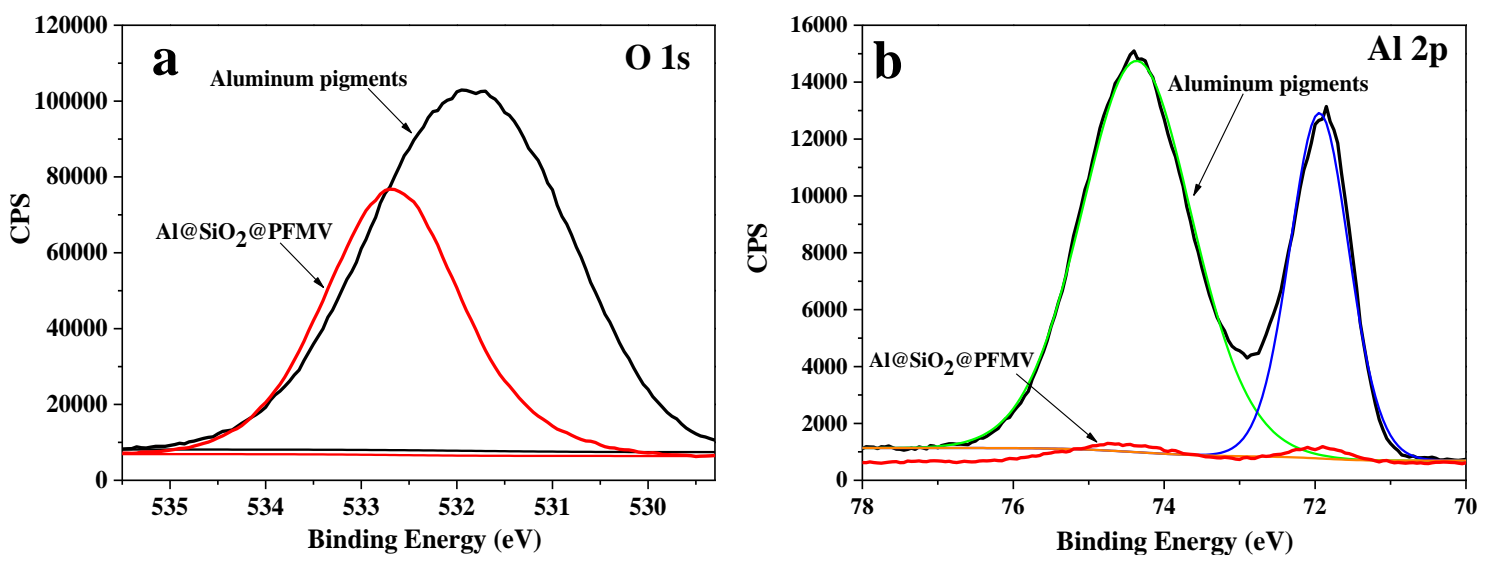

Figure 6. High-resolution XPS spectrum of $\mathrm{O} 1 \mathrm{~s}(\mathbf{a})$ and $\mathrm{Al} 2 \mathrm{p}(\mathbf{b})$.

\subsubsection{Particle Size Analysis}

To verify the size change of the aluminum pigments after the encapsulation, the particle size distribution was analyzed. The average diameter $\left(d_{50}\right)$ of colored aluminum pigments is about $28.23 \mu \mathrm{m}$ (Figure 7a), which is slightly larger than that of raw aluminum pigments with the size of $27.98 \mu \mathrm{m}$ (Figure $7 \mathrm{~b}$ ). The size change ascribed to the formed thin films on the surface of the raw aluminum pigments.
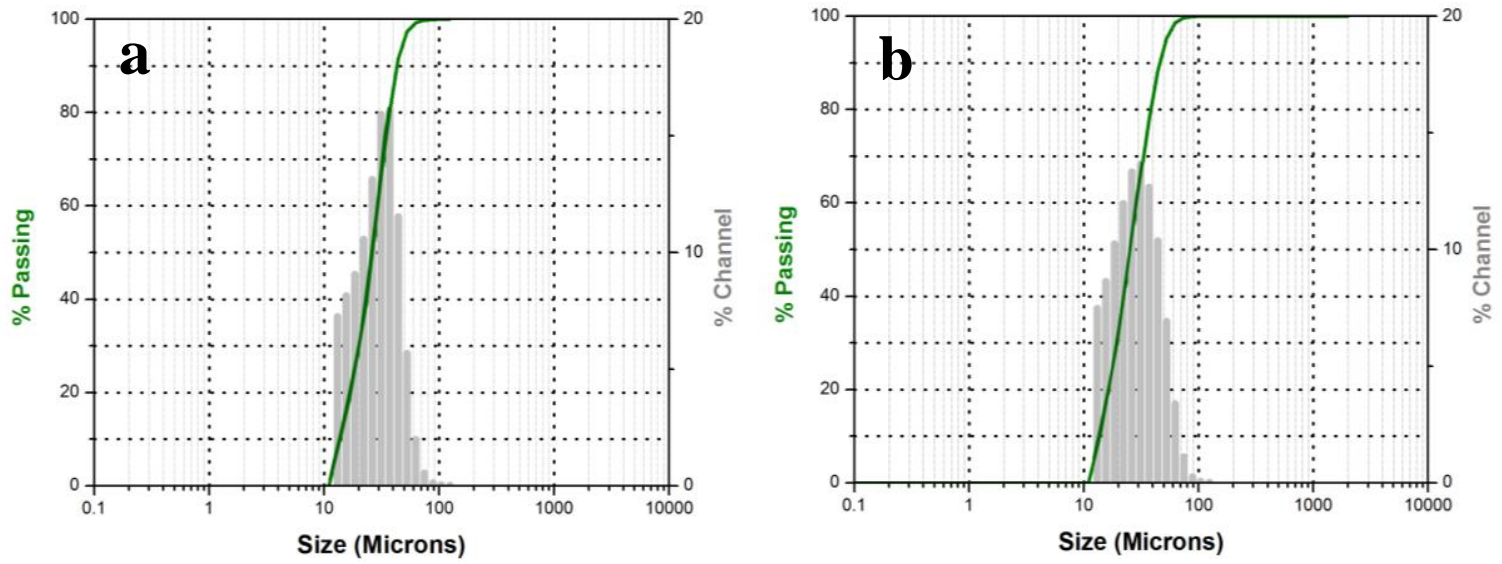

Figure 7. Particle size distributions of (a) raw aluminum pigments and (b) colored aluminum pigments.

\subsubsection{Morphologies of the Aluminum Pigments}

SEM was carried out for analyzing the surface morphology of aluminum pigments. Figure 8a indicated the raw aluminum pigments showed a smooth flaky powder. Figure $8 \mathrm{~b}$ showed the aluminum pigments were encapsulated by TEOS. PFMV co-hydrolyzed with TEOS was shown in Figure $8 \mathrm{c}$ ( $8 \mathrm{k}$ amplified factor) and Figure 8 (20k amplified factor). As can be seen from the Figure $8 \mathrm{~b}$, the $\mathrm{SiO}_{2}$ particles were uniformly distributed on the surface of aluminum pigment with size about $100 \mathrm{~nm}$. In contrast, we can find that the aluminum pigments were encapsulated in a dense film using 
PFMV and TEOS to form the inorganic-organic layer (Figure $8 c, d$ ). The surface of the aluminum pigments, which were coated by PFMV and TEOS, was more smooth than that of $\mathrm{Al}_{\mathrm{SiO}}$ in Figure $8 \mathrm{~b}$.
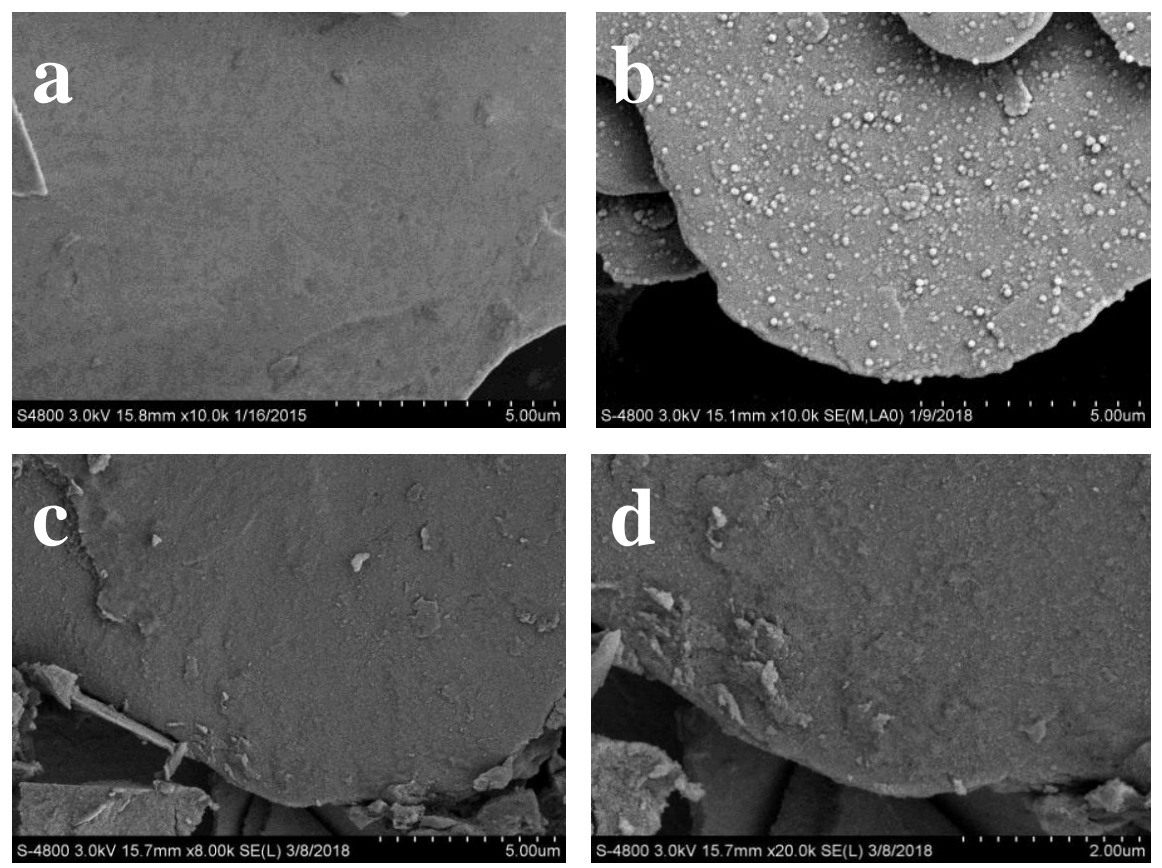

Figure 8. SEM images of raw aluminum pigments (a); $\mathrm{Al} @ \mathrm{SiO}_{2}$ (b); and $\mathrm{Al}_{\mathrm{S}} \mathrm{SiO}_{2} @ \mathrm{PFMV}(\mathbf{c}, \mathbf{d})$.

AFM was used to characterize surface roughness of the $\mathrm{Al}_{\mathrm{SSiO}}$ and $\mathrm{Al} @ \mathrm{SiO}_{2} @ \mathrm{PFMV}$. As shown in Figure $9 a, a^{\prime}$, it is obvious that there are many $\mathrm{SiO}_{2}$ particles formed on the surface of aluminum pigments, the maximum and average roughness of $\mathrm{SiO}_{2}$ particles were about $233.6 \mathrm{~nm}$ and $9.52 \mathrm{~nm}$,

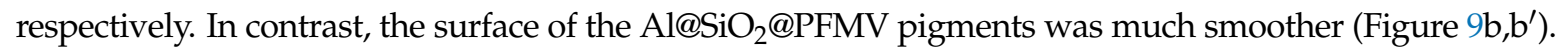
The maximum and average roughness were about $33.3 \mathrm{~nm}$ and $1.62 \mathrm{~nm}$, respectively. The topographical parameters, including the root mean square of the surface $\left(R_{\mathrm{q}}\right)$, the average roughness $\left(R_{\mathrm{a}}\right)$, and the maximum roughness $\left(R_{\max }\right)$, were shown in Table 2 . These results were consistent with the SEM results.
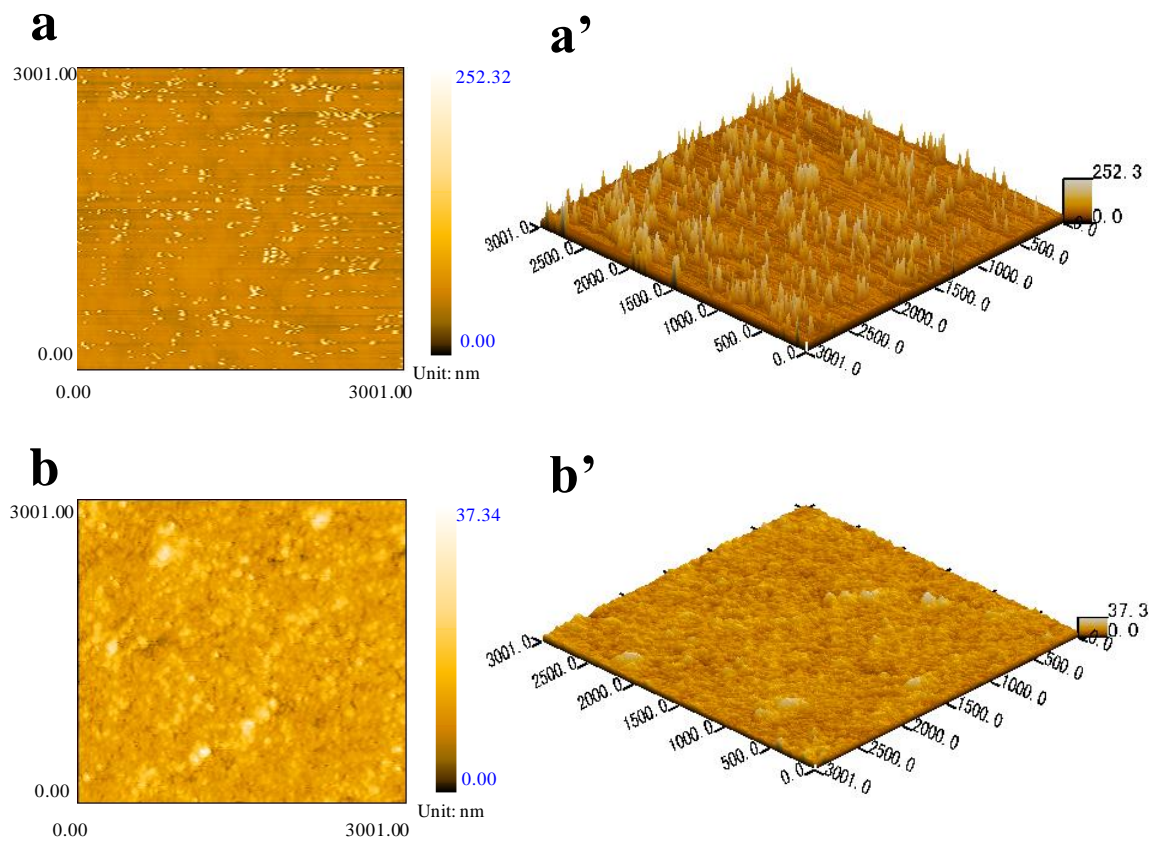

Figure 9. The AFM images of $\mathrm{Al} @ \mathrm{SiO}_{2}\left(\mathbf{a}, \mathbf{a}^{\prime}\right)$ and $\mathrm{Al} @ \mathrm{SiO}_{2} @ \mathrm{PFMV}\left(\mathbf{b}, \mathbf{b}^{\prime}\right)$. 
Table 2. The topographical parameters for $\mathrm{Al} @ \mathrm{SiO}_{2}$ and $\mathrm{Al} @ \mathrm{SiO}_{2} @ \mathrm{PFMV}$.

\begin{tabular}{cccc}
\hline Samples & $\boldsymbol{R}_{\mathbf{q}}(\mathbf{n m})$ & $\boldsymbol{R}_{\mathbf{a}}(\mathbf{n m})$ & $\boldsymbol{R}_{\max }(\mathbf{n m})$ \\
\hline $\mathrm{Al} @ \mathrm{SiO}_{2}$ & 9.64 & 9.52 & 233.6 \\
$\mathrm{Al} @ \mathrm{SiO}_{2} @ \mathrm{PFMV}$ & 1.65 & 1.62 & 33.3 \\
\hline$R_{\mathrm{q}}$ : the root mean square of the surface; $R_{\mathrm{a}}$ : the average roughness; $R_{\max }$ : the maximum roughness.
\end{tabular}

\subsubsection{TG Analysis}

Figure 10 showed the results of TG characterization of raw aluminum pigments and modified aluminum pigments. The quality of raw aluminum pigments decreased gradually with the increase of temperature range, which could be attributed to the decomposition of residual higher fatty acid or solvent oil used in the manufacturing process of aluminum pigments. The total weight loss values were about 3.0\%. For $\mathrm{Al}_{\mathrm{SiO}} @ \mathrm{PFMV}$, it was observed that the samples showed a multi-stage decomposition, and had a much faster decomposition rate, which may account for the PFMV decomposition on the surface of aluminum pigments. The total weight loss values of about $46 \%$, suggested that the PFMV have been hydrolyzed and condensed on the surface of aluminum pigments.

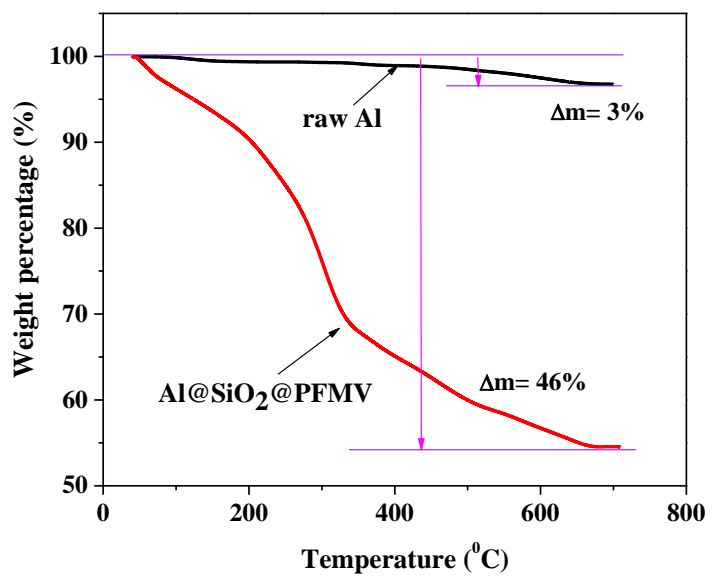

Figure 10. TG analysis of raw $\mathrm{Al}$ pigments and $\mathrm{Al} @ \mathrm{SiO}_{2} @ \mathrm{PFMV}$.

\subsection{Corrosion Resistance Tests}

To verify the combination of organic-inorganic mixed coating with the double-layer structure may bring better anticorrosion properties. The corrosion resistance of the raw aluminum pigments, $\mathrm{Al} @ \mathrm{SiO}_{2}$ and $\mathrm{Al} @ \mathrm{SiO}_{2} @ \mathrm{PFMV}$ were quantified by collecting the $\mathrm{H}_{2}$ gas at different time under $\mathrm{pH}$ 1.0 and $\mathrm{pH}$ 12. Clearly, the modified aluminum pigments have better stability than raw aluminum pigments. As shown in Figure 11, the $\mathrm{Al}_{\mathrm{SSiO}}$ and $\mathrm{Al} @ \mathrm{SiO}_{2} @ \mathrm{PFMV}$ pigments in the former $15 \mathrm{~h}$ can maintain good corrosion resistance in strong alkaline or acidic conditions. Both the $\mathrm{Al} @ \mathrm{SiO}_{2}$ and $\mathrm{Al} @ \mathrm{SiO}_{2} @ \mathrm{PFMV}$ formed a dense coating layer could prevent $\mathrm{Al}$ from reacting with the corrosive medium. After $20 \mathrm{~h}$, the collected gas volume from $\mathrm{Al}_{\mathrm{SiO}}$ is obviously higher than that of $\mathrm{Al} @ \mathrm{SiO}_{2} @ \mathrm{PFMV}$. We further extended the test time to $168 \mathrm{~h}$, as shown in Figure 12 , the volume of $\mathrm{H}_{2}$ evolved from the $\mathrm{Al}_{\mathrm{SiO}} @ \mathrm{PFMV}$ pigments was about one third that from $\mathrm{Al}_{2} @ \mathrm{SiO}_{2}$ at $\mathrm{pH} 1.0$ and $\mathrm{pH}$ 12. These results indicated that the protection efficiency of $\mathrm{Al}_{\mathrm{SSiO}} @ \mathrm{PFMV}$ with the double-layer structure was more efficient than the $\mathrm{Al} @ S i O_{2}$ with the single-layer coating. The grafting of the PFMV could further improve the corrosion resistance of $\mathrm{Al} @ S i O_{2}$ under the acid or alkali condition. 

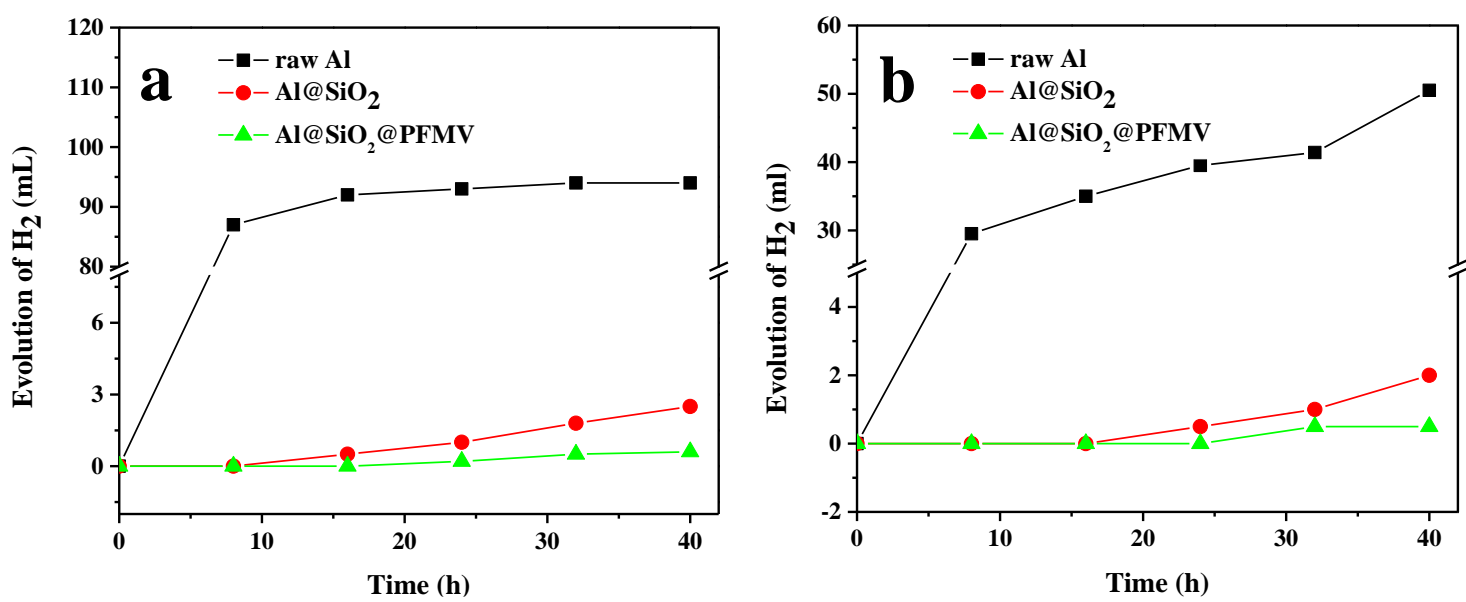

Figure 11. Corrosion resistance of raw aluminum pigments, $\mathrm{Al} @ \mathrm{SiO}_{2}$ and $\mathrm{Al} @ \mathrm{SiO}_{2} @ \mathrm{PFMV}$ at pH 1.0 (a) and at $\mathrm{pH} 12(\mathbf{b})$.
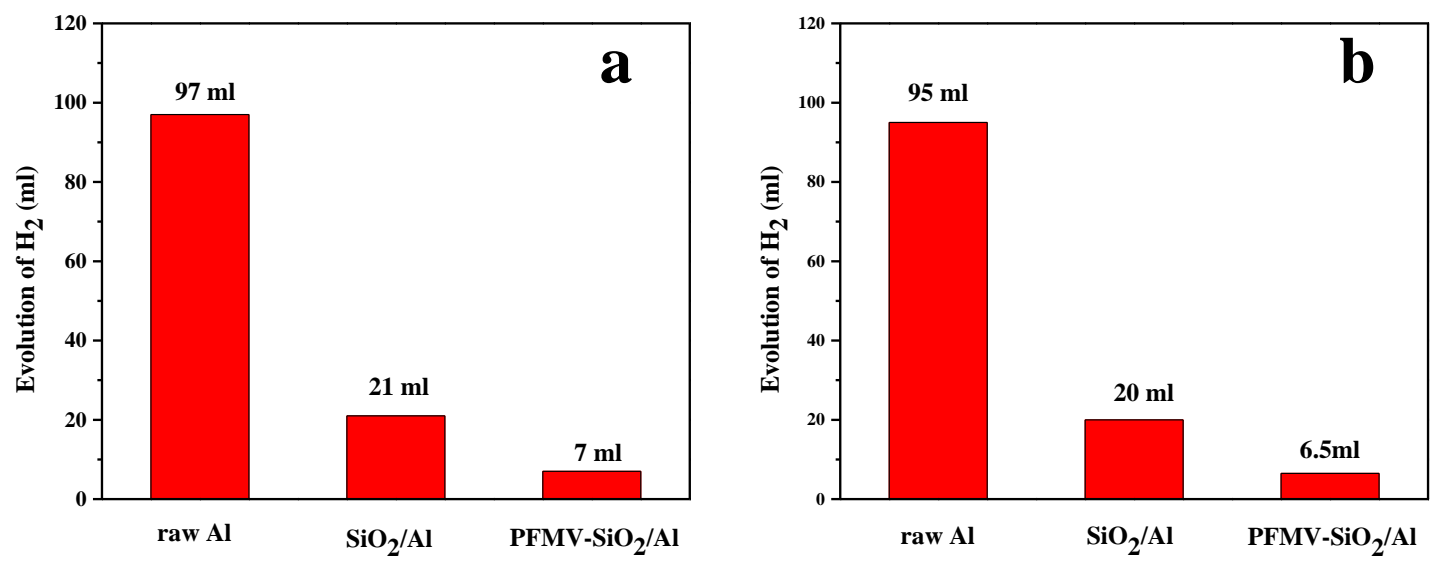

Figure 12. The volume of $\mathrm{H}_{2}$ evolved from the raw aluminum pigments, $\mathrm{Al} @ \mathrm{SiO}_{2}$ and $\mathrm{Al} @ \mathrm{SiO}_{2} @ \mathrm{PFMV}$ pigments within $168 \mathrm{~h}$ at $\mathrm{pH} 1.0(\mathbf{a})$ and at $\mathrm{pH} 12$ (b).

\subsection{Chromatism Analysis}

CIE $L^{*} a^{*} b^{*}$ is an important parameter to analyze the visible light optical properties, defined by the International Commission on Illumination. It expresses color as three values, $L^{*}$ for the lightness, $a^{*}$, and $b^{*}$ for the green-red and blue-yellow color components. The CIE $L^{*} a^{*} b^{*}$ values of raw aluminum pigments, $\mathrm{Al} @ \mathrm{SiO}_{2}$ and $\mathrm{Al} @ \mathrm{SiO}_{2} @ \mathrm{PFMV}$ were analyzed by the color analyzer. The results were listed in Table 3. When the test angle is $15^{\circ}$, the lightness of $\mathrm{Al}_{\mathrm{SiO}}$ and $\mathrm{Al} @ \mathrm{SiO}_{2} @ \mathrm{PFMV}$ slightly decreased compared to the raw aluminum pigments, which ascribe to that a dense film was formed on the surface of aluminum pigments. The values of $a^{*}$ and $b^{*}$ were -0.31 and -2.68 for aluminum pigments, respectively. For $\mathrm{Al} @ \mathrm{SiO}_{2} @ \mathrm{PFMV}$, the values of $a^{*}$ and $b^{*}$ were -1.61 and 14.04 . The $a^{*}$ value is slightly

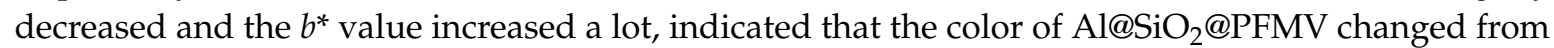
silver-gray to yellow. The CIE $L^{*} a^{*} b^{*}$ values were also measured with varying angles. From Table 3 , it can be found that the lightness of the pigments decreased with the increasing measuring angle for every sample. The $a^{*}$ and $b^{*}$ values for all the three sample changed little with the different angles. 
Table 3. The CIE $L^{*} a^{*} b^{*}$ values of aluminum pigments, $\mathrm{Al} @ \mathrm{SiO}_{2}$ and $\mathrm{Al} @ \mathrm{SiO}_{2} @ \mathrm{PFMV}$.

\begin{tabular}{|c|c|c|c|c|}
\hline \multicolumn{2}{|c|}{ Samples } & \multirow{2}{*}{$\begin{array}{c}\text { Aluminum Pigments } \\
159.3\end{array}$} & \multirow{2}{*}{$\frac{\mathrm{Al} @ \mathrm{SiO}_{2}}{136.86}$} & \multirow{2}{*}{$\begin{array}{c}\mathrm{Al} @ \mathrm{SiO}_{\mathbf{2}} @ \mathrm{PFMV} \\
111.6\end{array}$} \\
\hline & $L^{*}$ & & & \\
\hline $15^{\circ}$ & $a^{*}$ & -0.31 & -0.18 & -1.61 \\
\hline & $b^{*}$ & -2.68 & -0.53 & 14.04 \\
\hline \multirow{3}{*}{$25^{\circ}$} & $L^{*}$ & 109.68 & 109.82 & 94.04 \\
\hline & $a^{*}$ & -1.03 & -0.73 & -2 \\
\hline & $b^{*}$ & -1.79 & -0.27 & 15.03 \\
\hline \multirow{3}{*}{$45^{\circ}$} & $L^{*}$ & 52.35 & 67.04 & 68.64 \\
\hline & $a^{*}$ & -0.44 & -0.38 & -1.57 \\
\hline & $b^{*}$ & -1.19 & -0.27 & 14.56 \\
\hline \multirow{3}{*}{$75^{\circ}$} & $L^{*}$ & 31.73 & 41.27 & 49.5 \\
\hline & $a^{*}$ & -0.52 & -0.7 & -1.34 \\
\hline & $b^{*}$ & -0.94 & 0.55 & 16.59 \\
\hline \multirow{3}{*}{$110^{\circ}$} & $L^{*}$ & 26.22 & 34.11 & 41.51 \\
\hline & $a^{*}$ & -0.6 & -0.82 & -1.12 \\
\hline & $b^{*}$ & -1.1 & 0.82 & 18.5 \\
\hline
\end{tabular}

\section{Conclusions}

In this study, a novel cross-linked copolymeric dye PFMV was prepared and characterized. Yellow-colored aluminum pigments with the double-layer structure $\mathrm{Al} @ \mathrm{SiO}_{2} @ \mathrm{PFMV}$ were prepared by hydrolysis and condensation of PFMV and TEOS as precursor. The surface morphology and chemical structure of the colored aluminum pigments were characterized by SEM, AFM, and XPS. The PFMV and TEOS could form a dense and smooth inorganic-organic film coated at the surface of the raw aluminum pigments, which could not only improve their corrosion resistance, but also make the color change from silver-gray to yellow.

Author Contributions: M.C. (Ming Cao) and R.X. conceived and designed the experiments; Z.W. and M.C. (Ming Chen) conducted the IR, NMR, XPS and particle size measurement experiments; L.S. performed the AFM analysis; Y.L. performed the corrosion resistance tests; S.N. performed the chromatism analysis; Q.D., J.M., P.C., Z.Z., B.Y. and J.Q. analyzed the data. M.C. (Ming Cao) wrote the paper.

Funding: This research was funded by National Natural Science Foundation of China (No. 51403001), Anhui Provincial Natural Science Foundation (No. 1808085QE159) and Key Natural Science Project of Anhui Provincial Education Department (No. KJ2018A0035).

Conflicts of Interest: The authors declare no conflict of interest.

\section{References}

1. Ma, Z.L.; Li, C.C.; Wei, H.M.; Ding, D.Q. Silica sol-gel anchoring on aluminum pigments surface for corrosion resistance based on aluminum oxidized by hydrogen peroxide. Dyes Pigment. 2015, 113, 730-736. [CrossRef]

2. Du, B.; Zhou, S.S.; Li, N.L. Research progress of coloring aluminum pigments by corrosion protection method. Procedia Environ. Sci. 2011, 10, 807-813. [CrossRef]

3. Wang, K.; Wang, C.; Yin, Y.; Chen, K. Modification of Al pigment with graphene for infrared/visual stealth compatible fabric coating. J. Alloy. Compd. 2017, 690, 741-748. [CrossRef]

4. Liu, H.; Ye, H.; Tang, X. Aluminum pigment encapsulated by in situ copolymerization of styrene and maleic acid. Appl. Surf. Sci. 2007, 254, 616-620. [CrossRef]

5. Karlsson, P.; Palmqvist, A.E.C.; Holmberg, K. Surface modification for aluminium pigment inhibition. Adv. Colloid Interface Sci. 2006, 128, 121-134. [CrossRef] [PubMed]

6. Karlsson, P.M.; Baeza, A.; Palmqvist, A.E.C.; Holmberg, K. Surfactant inhibition of aluminium pigments for waterborne printing inks. Corros. Sci. 2008, 50, 2282-2287. [CrossRef]

7. Zhang, Y.; Ye, H.; Liu, H.; Han, K. Preparation and characterisation of aluminium pigments coated with silica for corrosion protection. Corros. Sci. 2011, 53, 1694-1699. [CrossRef] 
8. Nikravesh, B.; Ramezanzadeh, B.; Sarabi, A.A.; Kasiriha, S.M. Evaluation of the corrosion resistance of an epoxy-polyamide coating containing different ratios of micaceous iron oxide/Al pigments. Corros. Sci. 2011, 53, 1592-1603. [CrossRef]

9. Maayta, A.K.; Al-Rawashdeh, N.A.F. Inhibition of acidic corrosion of pure aluminum by some organic compounds. Corros. Sci. 2004, 46, 1129-1140. [CrossRef]

10. Muller, B. Citric acid as corrosion inhibitor for aluminium pigment. Corros. Sci. 2004, 46, 159-167. [CrossRef]

11. Mueller, B.; Fischer, S. Epoxy ester resins as corrosion inhibitors for aluminium and zinc pigments. Corros. Sci. 2006, 48, 2406-2416. [CrossRef]

12. El-Etre, A.Y. Inhibition of acid corrosion of aluminum using vanillin. Corros. Sci. 2001, 43, 1031-1039. [CrossRef]

13. Kiehl, A.; Greiwe, K. Encapsulated aluminium pigments. Prog. Org. Coat. 1999, 37, 179-183. [CrossRef]

14. Zhou, L.; Huang, S.L.; Kong, J.R.; Zhou, T.; Zuo, Y.J. Characterization of flaky aluminum pigments multi-coated by $\mathrm{TiO}_{2}$ and $\mathrm{SiO}_{2}$. Powder Technol. 2013, 237, 514-519. [CrossRef]

15. Liu, H.; Ye, H.; Zhang, Y. Preparation and characterization of PMMA/flaky aluminum composite particle in the presence of MPS. Colloid. Surf. A 2008, 315, 1-6. [CrossRef]

16. Liu, H.; Ye, H.; Zhang, Y.; Tang, X. Preparation and characterization of poly(trimethylolpropanetriacrylate)/flaky aluminum composite particle by in situ polymerization. Dyes Pigment. 2008, 79, 236-241. [CrossRef]

17. Karlsson, P.M.; Esbjörnsson, N.B.; Holmberg, K. Admicellar polymerization of methyl methacrylate on aluminum pigments. J. Colloid Interface Sci. 2009, 337, 364-368. [CrossRef] [PubMed]

18. Batzilla, T.; Tulke, A. Preparation of encapsulated aluminum pigments by emulsion polymerization and their characterization. J. Coat. Technol. 1998, 70, 77-83. [CrossRef]

19. Li, L.; Pi, P.; Wen, X.; Cheng, J.; Yang, Z. Optimization of sol-gel coatings on the surface of aluminum pigments for corrosion protection. Corros. Sci. 2008, 50, 795-803. [CrossRef]

20. Zhu, H.; Qu, X.; Hu, Y.; Xie, H.; Chen, Z. Corrosion inhibition of flaky aluminium powders prepared through sol-gel process. Corros. Sci. 2011, 53, 481-486. [CrossRef]

21. Zhu, H.; Chen, Z.; Sheng, Y.; Thi, T.T.L. Flaky polyacrylic acid/aluminium composite particles prepared using in-situ polymerization. Dyes Pigment. 2010, 86, 155-160. [CrossRef]

22. Joubert, M.; Save, M.; Mornet, S.; Lavaud, F.; Pellerin, V.; Morvan, F.; Tranchant, J.F.; Duguet, E.; Billon, L. Surface patterning of micron-sized aluminum flakes by seeded dispersion polymerization: Towards waterborne colored pigments by gold nanoparticles adsorption. Polymer 2014, 55, 762-771. [CrossRef]

23. He, Y.; Li, H.; Ou, L.; Ding, F.; Zhan, Z.; Zhong, Y. Preparation and characterisation of water-based aluminium pigments modified with $\mathrm{SiO}_{2}$ and polymer brushes. Corros. Sci. 2016, 111, 802-810. [CrossRef]

24. Tawiah, B.; Asinyo, B.K.; Badoe, W.; Zhang, L.; Fu, S. Phthalocyanine green aluminum pigment prepared by inorganic acid radical/radical polymerization for waterborne textile applications. Int. J. Ind. Chem. 2016, 8, 1-12. [CrossRef]

25. Zhang, Y.; Ye, H.; Liu, H.; Han, K. Preparation and characterization of colored aluminum pigments $\mathrm{Al} / \mathrm{SiO}_{2} / \mathrm{Fe}_{2} \mathrm{O}_{3}$ with double-layer structure. Powder Technol. 2012, 229, 206-213. [CrossRef]

26. Zhang, Y.; Ye, H.; Liu, H. Preparation and characterization of blue color aluminum pigments $\mathrm{Al} / \mathrm{SiO}_{2} / \mathrm{PB}$ with double-layer structure. Powder Technol. 2012, 217, 614-618. [CrossRef]

27. Tawiah, B.; Narh, C.; Li, M.; Zhang, L.; Fu, S. Polymer-encapsulated colorful Al pigment with high NIR and UV reflectance and their application in textiles. Ind. Eng. Chem. Res. 2015, 54, 11858-11865. [CrossRef]

28. Joubert, M.; Khoukh, A.; Tranchant, J.F.; Morvan, F.; Billon, L. Hybrid aluminum colored pigments based on gradient copolymers design. Macromol. Chem. Phys. 2009, 210, 1544-1555. [CrossRef]

29. Altomare, A.; Ciardelli, F.; Faralli, G.; Solaro, R. Synthesis of reactive polymeric dyes as textile auxiliaries. Macromol. Mater. Eng. 2003, 288, 679-692. [CrossRef]

30. Tawiah, B.; Zhang, L.; Tian, A.; Fu, S.S. Coloration of aluminum pigment using $\mathrm{SiO}_{2}$ and $\gamma$-glycidoxypropyltrimethoxysilane with dichlorotriazine reactive dye. Pigment Resin Technol. 2016, 45, 335-345. [CrossRef]

(C) 2018 by the authors. Licensee MDPI, Basel, Switzerland. This article is an open access article distributed under the terms and conditions of the Creative Commons Attribution (CC BY) license (http:/ / creativecommons.org/licenses/by/4.0/). 